\title{
IT learning sessions at Leeds Library and Information Service
}

\author{
Jason Tutin
}

\section{Abstract}

This report examines Leeds Library and Information Service's programme of IT learning sessions for the public. The report discusses how:

- Sessions are planned and delivered;

- Learners are engaged and recruited;

- Resources are used to support delivery;

- Learners are referred to other library services.

\section{Background}

Leeds Library and Information Service has delivered IT learning sessions to the public for over ten years. We deliver about 200 sessions every month and each year we see about 5,000 learners.

As a contract delivery partner for the council's Community Learning service, we claim Skills Funding Agency funding for some of our sessions. We have also had contracts to deliver careers advice sessions and have delivered a number of projects funded by UK Online centres. Over the years, the external quality systems required by different funding streams have included:

- Matrix Accreditation - A quality standard for Information, Advice and Guidance services. An assessor inspected our provision, examined our systems and processes and interviewed staff, learners and partners. We held the standard for six years from 2004 when we had a funded contract to deliver careers advice sessions.

- Community Learning Quality Team (CLQT) - Observers from the CLQT visit our sessions to inspect the quality of teaching, learning and assessment. The grading system used is the same as that used by OFSTED. Observation reports

\section{Author}

As Area Development Librarian for Learning at Leeds Libraries, Jason leads an IT Learning project team and coordinates the programme of public IT learning sessions.

Email: Jason.tutin@leeds.gov.uk 
are also used to inform the Community Learning Self Assessment Report, which is submitted annually to the Skills Funding Agency.

- Self Assessment Report (SAR) - Written by Libraries and submitted to the CLQT, the SAR is an annual review of our provision. Backed by evidence for the reasons behind the assessment, it highlights key strengths and areas for improvement in sections that include Outcomes for Learners and Effectiveness of Leadership and Management.

Those external requirements are in addition to our own internal monitoring and evaluation processes. For example, learners complete evaluation forms after every session. These are input to a database and analysed. The form includes space for learners to comment on their achievement, the quality of teaching and their satisfaction with the session. Last year, $91 \%$ of learners achieved everything they wanted on the session, $8 \%$ said they partly achieved what they wanted and only $1 \%$ said they did not achieve everything they wanted. In addition, $92 \%$ of learners said they were satisfied with their session and less than half of one percent were not satisfied.

We use all of these qualitative and quantitative indicators to develop and improve the way we manage and deliver our sessions.

\section{Planning and delivering our learning offer}

We have a programme of non-accredited IT learning sessions aimed at a general adult audience, available at all of our libraries and delivered by any of our Librarians or Development Librarians. We have a smaller number of nonaccredited sessions that are more specialised and only available at certain libraries, including some accredited provision at Studio12, a multimedia production studio at our Central library. These specialist sessions require specific equipment or resources to support them or specially trained staff to deliver them, or a combination of both. We also offer a number of sessions designed for jobseekers. These sessions focus on learning IT skills specifically as they relate to improving learners' employment prospects.

Our learning offer is set out in our Learn IT in the Library booklet. All sessions have learning outcomes devised by library staff, with space for learners to add their personal learning outcomes. Library staff use the booklet to promote the sessions at outreach events and to discuss a learner's requirements when they ask about a session in a library. The booklet is also available as a PDF download at: www.leeds.gov.uk/learning.

For many years we planned and advertised our sessions in advance each quarter. In effect, we were telling the public what they could learn, where and when: Basic Internet, Central Library, Friday 6 December, 10.00am. Despite our best intentions, we could not always be sure that our predictions would match people's needs or availability.

In January 2011 we piloted a system in one area of the city where sessions were planned and delivered in response to requests from the public. After that successful pilot, the system was extended to all libraries in March 2011. Now, almost all of our provision is available 'on request'. This means that we do not 
plan and advertise sessions in specific venues on specific dates and times. Instead, learners register their interest in a session by contacting any library. Their request is stored on a secure website and our Librarians contact every learner by telephone. During this phone call an initial assessment is also carried out, any specific needs are identified and sessions are arranged at times and at venues to suit both library staff and the learners. The only exceptions to this way of working are specialist drop-in sessions such as Work Clubs and Studio12 sessions. Our specialist sessions and the resources we have in place to support them, including staff training, will be discussed in more detail later in this article.

In practice, this way of working means that we are only delivering sessions that people want, in venues that are suitable and at times when they are available. If a number of people request the same session and are available at the same time, we will arrange to deliver the session to a small group. If only one person wants a particular session at a particular library, we will arrange to see that person on a one-to-one basis. Each session lasts for one hour if delivered as a one-to-one session, or 90 minutes if delivered to a small group of learners.

Learners usually book one session at a time rather than booking a course of sessions over a number of weeks. This means that learners are free to request sessions wherever and whenever it suits them. A four week course comprising our most basic sessions is available in some libraries for people who wish to commit to more sessions in advance. This course also helps our staff to track learners' progress over a longer timeframe.

Our learning offer is both highly flexible and tightly defined. The public are offered a wide range of sessions, covering a range of topics from the most basic IT skills through to specific areas of interest. People can choose the sessions that most interest them and learn the skills they need to achieve their goals. There is no fixed enrolment date and there is no minimum class size to make the provision viable. This, coupled with the geographic spread of venues, means that learners have the choice of hundreds of sessions across multiple sites. This flexible approach is popular with the public and means that the service is constantly responding to community need. At the same time, our staff know that there is a fixed number of sessions that they will be asked to deliver, each with defined learning outcomes. Any staff training needs can be identified and addressed so that groups of staff within each geographical team have the skills to deliver all of the sessions in the programme.

\section{Engaging and recruiting learners}

Some of our provision is aimed at specific target audiences and we engage and recruit them in different ways. For example, the target group for our IT for Employment sessions is jobseekers. These learners will be people are unemployed or underemployed, with relatively little IT skills or experience. We also find that even if people have some IT skills, they have never applied those skills to the more formal tasks of job searching, writing application forms or designing a CV.

We have a successful track record of engaging and recruiting this target group. We work with some of the jobshops across Leeds who refer some of their learners to specially arranged IT for Employment sessions in the library. In 2010 two Joint 
Service Centres opened and those buildings include a library, a jobshop, other council services and partners. This made the referral process between the library and the jobshop even easier and made learners more comfortable with attending a learning session in the same venue. We also have a Service Level Agreement and a referral system in place across the city with Jobcentre Plus. Staff in jobcentres can phone a single number to book a client onto one of our Jobseeker Advice sessions.

In 2011 we started to run Work Clubs in some of our libraries. We currently run Work Clubs at four libraries, two in partnership with National Careers Service and all supported by Jobcentre Plus. Clubs run weekly or fortnightly on a drop-in basis. This is an opportunity to offer taster sessions to learners and assess their need. The Work Clubs are advertised across the city and some of the services on offer include:

- Support to find and research job opportunities with help from qualified library staff and partners;

- CV preparation workshops;

- A chance to share experiences with other work club attendees;

- IT workshops such as setting up email, finding jobs online, writing application forms and covering letters.

Learners are referred as appropriate between our general learning sessions, IT for Employment sessions, Work Clubs and Studio 12.

Studio12 is an audio visual media project providing access to a production studio, training and accredited qualifications. Sessions take place at the production space in Leeds Central Library. The target group for Studio12 is people aged 16 - 30, with priority given to people not in education and employment. Studio12 learners often have existing IT skills and want to develop their skills in relation to digital media and new technology. To engage those learners, Studio12 has an increased online presence, including its own website and YouTube channel. Studio12 also works with other arts and media organisations.

For our sessions aimed at a general audience, the target group is any adult who wants to improve their IT skills. This universal provision matches the wider library service, which is open to everyone from any section of the community. Libraries are seen as informal, neutral, non-threatening venues. Potential learners for our general sessions may already use the library for other things and so learning in the library is not seen as a significant step in the way that enrolling at college might be perceived. Most of our sessions take place in the public area of the library while the library is open. This means that library users can see the sessions happening, which may encourage them to ask about future sessions. Our sessions are delivered by library staff and learners may already know those staff in another role at the library, from helping a child with their homework to issuing books. Again, this helps to reduce the fear of learning that some people may still carry with them.

Having engaged learners from different target groups, we find it relatively easy to recruit them. Libraries are well placed to overcome many of the barriers to 
learning that prevent some people from taking part. Attitudinal barriers to learning and a general lack of confidence often prevent learners from taking the first step back into learning. In a library setting these perceptions are often reduced. We are not seen as a 'traditional' learning establishment, which helps to overcome any negative feelings people may have about previous unsuccessful experiences at school or college. We are not asking people to sign up to a long course over a number of weeks where they have to learn a set curriculum with classmates who they may perceive as more knowledgeable or more experienced.

Other barriers to learning may be organisational. A venue may say that they will only accept learners who meet certain criteria. Those criteria may be based on geography, academic attainment or eligibility for certain benefits. Leeds libraries do not put up any of those barriers. We will work with anyone who wants to attend a learning session and our sessions are advertised on that universal basis.

Financial barriers to learning are particularly important for some people. With so many libraries spread around the city, travel costs to attend our sessions are kept to a minimum. With unemployment and under-employment rates particularly high for certain minority ethnic communities, language barriers may be another issue. We have staff who can deliver IT for Employment sessions in a range of community languages.

Our success in engaging and recruiting learners is demonstrated by the number of session requests we receive. In addition to our drop-in provision, we get over 100 requests for learning sessions every week.

\section{Resources to support delivery}

All of our sessions have associated lesson plans for staff and handouts for learners. We have libraries across the city with 500 computers available for public use. These are the venues and PCs that we use to deliver our sessions. In two libraries we have self-contained learning suites with interactive whiteboards and in our Central Library we have Studio12, a multimedia production studio.

We have a team of Librarians and Development Librarians who deliver the sessions. They have specific libraries where they deliver the majority of their sessions, but also have a citywide remit to cover for colleagues' absence or deliver more specialised sessions. This increases our coverage and capacity to deliver in all of our libraries. None of these staff are qualified teachers or full-time tutors and they all have other library duties as part of their role. To equip them with the skills they need to deliver the sessions, we offer two strands of training:

1. Training so that staff are more confident using specific pieces of hardware and software.

This IT training includes formal training options such as ECDL or ITQ. It also includes informal training delivered in-house by more experienced colleagues or by partners. For example, Boardmaker symbol software is used by parents and professionals to improve communication with children and young people who have disabilities or specific needs that affect their verbal communication. When we installed Boardmaker in Leeds Libraries, we organised a training session for our Librarians delivered by partners from the Speech and Language Therapy 
service and Specialist Autism Teachers. When the Universal Jobmatch website was launched, we organised training and awareness briefings from our partners in Jobcentre Plus.

2. Training so that staff are more confident at delivering sessions.

Again, this includes formal and informal options. Most of our Librarians have gained the PTLLS qualification at Level 3 or Level 4. PTLLS is Preparing to Teach in the Lifelong Learning Sector and it provides an introduction to anyone whose role includes the teaching or training of adults. As the number of unemployed people attending our sessions has increased, some staff have chosen training to help them work with this client group more effectively. Some staff have gained qualifications at Level 3 or 4 in Information, Advice and Guidance (IAG). Others have taken the OCR Level 3 Award 'Supporting clients to overcome barriers to learning and work'. Informally, staff can shadow more experienced colleagues or attend sessions with partners to increase their confidence.

We have specialist hardware and software to support specific sessions. At Studio12 we have HD cameras, digital SLR cameras, photography and film studios, keyboards, scanners, and graphics tablets. We also have a range of software including: Reason, Cubase, Adobe Premier, Final Cut Pro, Photoshop, 3D Studio Max, Cinema 4D, Flash, Dreamweaver and After Effects. Studio12 also offers accreditation in the form of two 30 hour courses covering Audio Visual Media Production skills at Level 2 or Level 3. Industry standard software and hardware and the chance to achieve accreditation or complete a portfolio of evidence is part of Studio12's attraction to learners.

Even our general IT learning sessions make use of specific online resources to which the library service has subscribed. We show people how to use the Ancestry website on our family history sessions. We use the Life in Great Britain website when talking to groups or individuals who may be preparing for their citizenship test. As well as adding value to our sessions, these resources encourage learners to continue using library services after their session.

\section{Links to other library services and further learning}

We deliver hundreds of IT learning sessions every month and our capacity to deliver more sessions is limited. We need to respond to new requests by creating space for new learners on the hundreds of sessions we already deliver. The only way to create that space is to ensure we have a regular turnover of learners. Those people who have already attended multiple sessions need to move on so that we continue to have space for new people.

To achieve this, our programme of sessions has two additional intended outcomes: to equip people with the skills to continue their learning outside of our sessions and to signpost them to other library services and learning opportunities.

We encourage learners to ask questions on our sessions and to clarify things if they're uncertain. We want our sessions to give learners the confidence to further their learning, rather than to let their uncertainty or lack of confidence inhibit their learning. We use handouts on our sessions designed by library staff. We refer 
people to our non-fiction books and we show them how to use the online library catalogue as part of our internet sessions. Learning to use the internet to solve PC problems or to continue the learning journey is an integral part of our sessions. We highlight e-learning websites, message boards, forums and websites that contain user guides or video tutorials.

Some of these sites also give us the opportunity to discuss wider information literacy issues with our learners. For example, most of the websites with video content also contain videos on how to do lots of other things - some of which we would not encourage in a public library! But that can be a useful introduction to the subjects of internet safety and information literacy online. It also opens up discussion about Web2.0 and user-generated content.

In addition to promoting self-directed learning, we also discuss progression opportunities with learners at the end of our sessions. This may be progression onto another IT learning session, but it may also be a referral to another library service or a service delivered by another organisation.

The library services to which we most frequently refer learners are part of our Business and Patents Information Service, based at our Central Library: www.businessandpatents.org. Here, learners can get support with their business and intellectual property enquiries. As well as organising citywide partnership events, the service runs regular smaller scale events such as:

- Enterprise club. A chance to network and access information, support and advice on starting and running a business;

- Inventors club. Meet other inventors, get advice from people involved in the business of protecting and exploiting new ideas and products;

- Patent clinic. Confidential one-to-one consultation with a registered patent attorney.

Other specialist services at our Central library include:

- Studio12. The chance to build a portfolio of work, gain an accredited qualification and work with new media;

- Local and Family history department. 180,000 items including books, journals, directories, maps, photographs, prints, playbills and microfilms;

- Information centre. Reference and research resources with over 250,000 books, journals and newspapers. Particular strengths include history, literature and historical biography, law and rights and Europe Direct Leeds.

Referring learners to these services is usually quite straightforward, but some learners need more detailed IAG as part of their referral. This is especially true for learners who are accessing our IT for Employment provision. Although we do have some staff with IAG qualifications, our capacity to deliver higher level IAG is limited. To compensate, we work in partnership with other organisations. For example, National Careers Service advice workers are available in some libraries and our staff signpost learners to those advisers if library advisers are unavailable. At the same time, National Careers Service advice workers signpost their clients to learning sessions in libraries. 
Our staff's ability to refer learners to other organisations is enhanced by the relationships we have in place with those organisations. Our history of securing funding contracts for our sessions makes it easier for us to develop referral pathways, such as those with Jobcentre Plus, jobshops and National Careers Service. Other organisations see us at network meetings for contract delivery partners and similar forums. They know that, like them, we won the contract by successfully completing a competitive tendering process. As such, they have confidence that our session delivery, monitoring systems and reporting processes are of sufficient quality to meet those external contract requirements. Achieving those standards has strengthened our partnerships and referral networks. Stronger partnerships have led to more training and development opportunities for our staff.

As a result of all of these factors, Leeds Library and Information Service continues to deliver a coherent programme of IT learning sessions to the public. It is a service which is responsive, evolving and constantly improving to meet the needs of our communities.

\section{Open access and copyright}

Library and Information Research is an open access journal. A freely available copy of this paper may be downloaded from the journal's website:

http://www.cilipjournals.org.uk/lir

Copyright and associated moral rights in works published in Library and Information Research are retained by the author(s) but this paper may be used freely, with proper attribution, in educational and other non-commercial settings. 